\title{
Intravenous zoletil administration for the purpose of suicide
}

\section{Kyungman Cha, Won Jung Jeong, Hyung Min Kim, Byung Hak So}

Department of Emergency Medicine, St. Vincent's Hospital, The Catholic University of Korea College of Medicine, Suwon, Korea

Zoletil is a combination of tiletamine hydrochloride and zolazepam hydrochloride used as a veterinary anesthetic. Although zoletil abuse is widely known, zoletil poisoning for the purpose of suicide is very rare. We present a case of a 39-year-old man who attempted suicide by intravenously injecting a large amount of zoletil, resulting in decreased mental status and severe respiratory depression. Intubation and mechanical ventilation were applied. After 30 hours in the hospital, all symptoms of poisoning improved. Because zoletil can cause severe respiratory depression, close observation and aggressive securement of an airway is mandatory.

Keywords Poisons; Zolazepam; Tiletamine; Suicide

\section{INTRODUCTION}

Zoletil is a veterinary anesthetic for dogs, cats, wild animals, and zoo animals. ${ }^{1,2}$ It consists of tiletamine hydrochloride, an arylminocycloalkanone dissociative anesthetic, and zolazepam hydrochloride, a nonphenothiazine diazepinone, both of which are distributed in Korea in products at $125 \mathrm{mg}$ each. ${ }^{3}$ The potential for zoletil abuse by health care professionals and veterinarians is widely known ${ }^{4,5}$. Before being designated as a regulated psychotropic drug in Korea in 2015, zoletil was easily accessible to the public. Deaths caused by its misuse have been reported. ${ }^{6,7}$

Acute poisoning for the purpose of suicide is generally caused by a larger amount of a substance than is unintentional poisoning or poisoning due to abuse. It is very rare for tiletamine/ zolazepam to be directly injected into a vein. We report a case in which a man attempted suicide by intravenously injecting 1,500 mg of zoletil. He consequently experienced decreased consciousness and dyspnea, but eventually recovered.

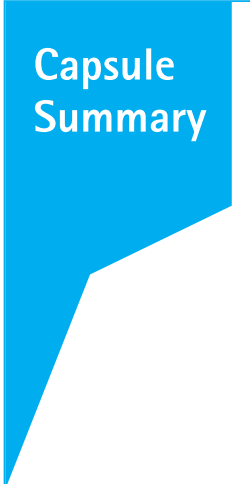

What is already known

Zoletil, a veterinary anesthetic, is generally abused for recreational purposes. Poisoning for suicide attempts is very rare.

What is new in the current study

Acute poisoning of a large amount zoletil in a suicide attempt results in severe poisoning symptoms and signs, including decreased level of consciousness, hypopnea, acidosis, and hypercapnia.
eISSN: 2383-4625

Received: 15 May 2020

Revised: 6 July 2020

Accepted: 14 July 2020

Correspondence to: Byung Hak So Department of Emergency Medicine, St. Vincent's Hospital The Catholic University of Korea College of Medicine, 93 Jungbu-daero, Paldal-gu, Suwon 16247, Korea

E-mail:sohak@catholic.ac.kr ORCID

https://orcid.org/0000-0003-0383-9197

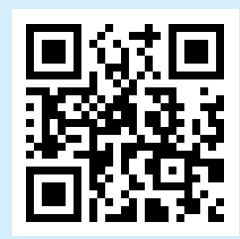

How to cite this article:

Cha K, Jeong WJ, Kim HM, So BH. Intravenous zoletil administration for the purpose of suicide. Clin Exp Emerg Med 2021;8(2):149-151. https://doi. org/10.15441/ceem.20.050

This is an Open Access article distributed under the terms of the Creative Commons Attribution Non-Commercial License (https:// creativecommons.org/licenses/by-nc/4.0/). 


\section{CASE REPORT}

Owing to migraine and abdominal pain, a 39-year-old man visited a local clinic where he received intravenous (IV) treatment. However, his consciousness decreased rapidly after going to the toilet, and he was transferred to the emergency department (ED). His initial Glasgow Coma Scale (GCS) score was 6. Initial vital signs were as follows: blood pressure, 120/80 mmHg; pulse rate, 90 beats per minute; breathing rate, 28 breaths per minute; body temperature, $36.9^{\circ} \mathrm{C}$ and peripheral oxygen saturation $\left(\mathrm{SpO}_{2}\right)$, $98 \%$. Physical examination showed equal 3-mm pupils with a normal pupillary light reflex and a scar from a lacerated wound on his left wrist; otherwise, the results were unremarkable.

The patient's family stated that he had stopped taking prescribed medications for schizophrenia 1 year ago, causing his hallucinations and delusions to worsen. Ten days prior to the ED visit, the patient cut his wrist with a knife. The medical team suspected this case to be an attempted suicide by poisoning and found a 50- $\mathrm{mL}$ syringe and a receipt for an animal anesthetic in the patient's bag. As confirmed by the supplier, the patient had purchased six vials of Zoletil 50 (125 mg tiletamine hydrochloride, $125 \mathrm{mg}$ zolazepam hydrochloride).

A 12-lead electrocardiogram showed a normal sinus rhythm. There were no abnormalities on chest radiography or brain computed tomography or in the complete blood count and blood chemistry results. One hour after admission, arterial blood gas analysis (ABGA) revealed the following: $\mathrm{pH}_{1} 7.29 ; \mathrm{PaO}_{2}, 183.9 \mathrm{mmHg}$; $\mathrm{PaCO}_{2}, 48.7 \mathrm{mmHg} ; \mathrm{HCO}_{3}{ }^{-}, 24.1 \mathrm{mmol} / \mathrm{L}$; and $\mathrm{SaO}_{2}, 99.9 \%$ at a $\mathrm{FiO}_{2}$ of 0.44 . Two hours after admission, the patient's breathing weakened and $\mathrm{SpO}_{2}$ level decreased to 85\%. Endotracheal intubation was performed, and oxygen was provided at $7 \mathrm{~L}$ per minute. The $A B G A$ results right after intubation were as follows: $\mathrm{pH}$, 7.19; $\mathrm{PaO}_{2}, 257.2 \mathrm{mmHg} ; \mathrm{PaCO}_{2}, 71.1 \mathrm{mmHg} ; \mathrm{HCO}_{3}{ }^{-}, 28.0 \mathrm{mmol} / \mathrm{L} ;$ and $\mathrm{SaO}_{2}, 99.9 \%$. Mechanical ventilation was applied to help the patient breathe. Four hours after intubation, the $\mathrm{pH}, \mathrm{PaO}_{2}, \mathrm{PaCO}_{2}$, $\mathrm{HCO}_{3}{ }^{-}$, and $\mathrm{SaO}_{2}\left(\mathrm{FiO}_{2}\right)$ were $7.38,121.8 \mathrm{mmHg}, 37.8 \mathrm{mmHg}, 22.5$ $\mathrm{mmol} / \mathrm{L}$, and $99.3 \%(0.3)$, respectively.

The patient remained hemodynamically stable without muscle rigidity or pulmonary edema. Twenty hours after admission, his consciousness recovered. He was extubated, and the mechanical ventilator was removed. The ABGA results were as follows: $\mathrm{pH}$, 7.40; $\mathrm{PaO}_{2}, 78.2 \mathrm{mmHg} ; \mathrm{PaCO}_{2}, 37.4 \mathrm{mmHg} ; \mathrm{HCO}_{3}{ }^{-}, 23.7 \mathrm{mmol} / \mathrm{L} ;$ and $\mathrm{SaO}_{2}$ 95.9\% (room air), and his GSC score was 14 . He felt sleepy, shouted intermittently, and seemed irritated. At 30 hours, GCS score was 15 , and the results of physical and neurological examinations were normal.

The patient confirmed that he had purchased six vials of Zoletil
50 before visiting a local clinic for IV treatment. When the IV solution was almost gone (about 1 hour before the ED visit), he mixed Zoletil 50 with the IV solution using a syringe while in the restroom. The total dose of zoletil was 1,500 $\mathrm{mg}(21.4 \mathrm{mg} / \mathrm{kg})$. He was transferred to the department of neuropsychiatry 3 days postadmission for further observation.

\section{DISCUSSION}

Tiletamine is a phencyclidine derivative that causes deep analgesia, while zolazepam has minor tranquilizing properties. Zoletil contains equal amounts of tiletamine and zolazepam. ${ }^{8}$ It induces anesthesia very quickly, causing the breathing rate of the injected animal to double for 15 minutes, the tidal volume to decrease to less than half of the control value, and the oxygen saturation level to decrease. Side effects reported in animals include excessive salivation, vomiting, muscle rigidity, hypertonicity, central nervous system stimulation, seizures, pulmonary edema, apnea, hypothermia, a prolonged recovery time, tachycardia, hypertension, and hypotension. High doses can cause respiratory depression and death. Zoletil poisoning in humans is very rare and usually related to drug abuse. Syncope, decreased mental status, and involuntary movement are some of the accompanying symptoms. ${ }^{4,5}$

In rats, the reported oral 50\% lethal dose of zoletil is $160 \mathrm{mg} / \mathrm{kg}$ of tiletamine and $398 \mathrm{mg} / \mathrm{kg}$ of zolazepam. ${ }^{3}$ Zoletil is injected intramuscularly or intravenously; on average, tiletamine and zolazepam reach their peak plasma concentrations 31.92 minutes and 65.17 minutes after zoletil injection, respectively. ${ }^{9}$ When tranquilizing polar bears, $5.0 \mathrm{mg} / \mathrm{kg}$ of tiletamine/zolazepam is effective, while $3.6 \mathrm{mg} / \mathrm{kg}$ is used for chimpanzees. A dose of $8.25 \mathrm{mg} / \mathrm{kg}$ of tiletamine is fatal for gorillas after 5 hours with death due to respiratory depression. ${ }^{1}$ The fatal toxic level of zoletil alone in human is unknown.

Previous cases of zoletil poisoning before zoletil regulation in Korea have been reported. These include a 45 -year-old man whose postmortem toxicological analysis revealed the presence of zolazepam, ketamine, and a maximum level of $9.6 \mathrm{mg} / \mathrm{kg}$ of tiletamine; a 30-year-old woman whose consciousness decreased but recovered without intubation after injection of approximately $200 \mathrm{mg}$ of telazol (which contains tiletamine and zolazepam); a 30-yearold man who injected 9 ampules of zoletil (tiletamine $125 \mathrm{mg}+$ zolazepam $125 \mathrm{mg} / 5 \mathrm{ml}$ ) for 9 consecutive days and received emergency treatment for tremors, hypersalivation, and general weakness; and an 83-year-old woman who was intramuscularly injected with seven vials of Zoletil 50 by her daughter, resulting in an altered mental status. ${ }^{4,7,10,11}$ Despite the regulation of zoletil, the potential for its abuse by veterinarians and veterinary staff still 
remains owing to its relatively easy procurement.

The patient in this case report overdosed on a total of 1,500 mg $(21.4 \mathrm{mg} / \mathrm{kg})$ of zoletil. This is the largest dose of IV zoletil overdose case reported and is potentially lethal. Although the patient showed symptoms of respiratory depression and decreased consciousness, he recovered after intubation and mechanical ventilation without any antidote treatment. Hypercapnia, and acidosis severe enough to require intubation were observed. Hypopnea likely worsens in humans as the dosage of zoletil increases; it is insignificant in dogs but causes acidosis, hypercapnia, and hypoxemia in cats depending on its dosage. ${ }^{12,13}$ Time- and dose-dependent hypertension has been observed in rats tranquilized with tiletamine/zolazepam, however our patient did not have elevated blood pressure. $^{14}$

In conclusion, acute injection of a large amount of zoletil for the purpose of suicide causes severe symptoms, including decreased consciousness, hypopnea, acidosis, and hypercapnia. Treatments such as intubation and artificial ventilation can rapidly improve the symptoms of zoletil poisoning within 24 hours.

\section{CONFLICT OF INTEREST}

No potential conflict of interest relevant to this article was reported.

\section{REFERENCES}

1. Haigh JC, Stirling I, Broughton E. Immobilization of polar bears (Ursus maritimus Phipps) with a mixture of tiletamine hydrochloride and zolazepam hydrochloride. J Wildl Dis 1985;21: 43-7.

2. Sweitzer RA, Ghneim GS, Gardner IA, Van Vuren D, Gonzales BJ, Boyce WM. Immobilization and physiological parameters associated with chemical restraint of wild pigs with Telazol and xylazine hydrochloride. J Wildl Dis 1997;33:198-205.
3. Lin HC, Thurmon JC, Benson GJ, Tranquilli WJ. Telazol: a review of its pharmacology and use in veterinary medicine. J Vet Pharmacol Ther 1993;16:383-418.

4. Quail MT, Weimersheimer $P$, Woolf $A D$, Magnani B. Abuse of telazol: an animal tranquilizer. J Toxicol Clin Toxicol 2001;39: 399-402.

5. Lee CC, Lin YY, Hsu CW, Chu SJ, Tsai SH. Movement disorder caused by abuse of veterinary anesthesia containing tiletamine. Am J Emerg Med 2009;27:1022.E5-6.

6. Chung $H_{1}$ Choi $H_{1}$ Kim $E_{1}$ Jin W, Lee $H_{1}$ Yoo Y. A fatality due to injection of tiletamine and zolazepam. J Anal Toxicol 2000; 24:305-8.

7. Lee $Y K$, Kang IG, Park CS, et al. A case of mental change in a patient who received a zoletil injection. J Korean Soc Clin Toxicol 2013;11:23-7.

8. Kaufman PL, Hahnenberger R. Cl-744 anesthesia for ophthalmological examination and surgery in monkeys. Invest Ophthalmol 1975;14:788-91.

9. Kumar A, Mann HJ, Remmel RP. Pharmacokinetics of tiletamine and zolazepam (Telazol) in anesthetized pigs. J Vet Pharmacol Ther 2006;29:587-9.

10. Cording CJ, DeLuca R, Camporese T, Spratt E. A fatality related to the veterinary anesthetic telazol. J Anal Toxicol 1999;23: 552-5.

11. Wang I, Yeom S, Kim Y. A case of zoletil, veterinary anesthetic poisoning. J Korean Soc Emerg Med 2013;24:122-4.

12. Hellyer P, Muir WW 3rd, Hubbell JA, Sally J. Cardiorespiratory effects of the intravenous administration of tiletamine-zolazepam to cats. Vet Surg 1988;17:105-10.

13. Stirling I, Spencer C, Andriashek D. Immobilization of polar bears (Ursus maritimus) with Telazol in the Canadian Arctic. J Wildl Dis 1989;25:159-68.

14. Wilson RP, Zagon IS, Larach DR, Lang CM. Cardiovascular and respiratory effects of tiletamine-zolazepam. Pharmacol Biochem Behav 1993;44:1-8. 